\title{
Historia social de la asistencia hospitalaria de la Andalucía moderna: El caso de Cabra (Córdoba)
}

Francisco de Borja* Luque Muriel

En nuestros días el término "hospital» se asocia inmediatamente al de "Centro Sanitario", un lugar regido fundamentalmente con fondos públicos y destinado en exclusiva para el remedio de nuestros males físicos o enfermedades temporales. Sin embargo, este carácter queda alterado al referirnos a los hospitales existentes en la Edad Moderna.

El hospital, durante la Edad Media y el Antiguo Régimen, era una institución esencial en la vida de toda comunidad, no sólo por la asistencia a pobres enfermos en una época en que la guerra y, principalmente, el hambre y las epidemias fueron habituales, sino también porque el hospital es un centro que se inserta íntimamente en la sociedad. $Y$ desde esta institución se puede estudiar la evolución social de la época en una comunidad determinada.

A partir de estas premisas intentaremos presentar la aproximación al estudio social de la asistencia hospitalaria en Andalucia, atendiendo al caso de Cabra, concluyendo con un avance de las posibles líneas de investigación que nos permite la documentación.

\footnotetext{
* Secretario del Centro Asociado de Córdoba.
} 


\section{DE LA COFRADÍA DE LA CARIDAD AL HOSPITAL DE SAN RODRIGO: ...-1586}

La primera etapa de la asistencia hospitalaria en Cabra viene caracterizada por la dirección de los hospitales por parte de la Cofradia y Hermandad de la Santa Caridad. Hemos hablado de hospitales, en plural, pues los documentos conservados nos indican la existencia a principios del siglo XVI de dos centros: el hospital de Santa Maria, para pobres naturales de la villa, y el de Corpus Christi, para peregrinos extranjeros.

Esta dualidad hospitalaria, regida por una misma institución, se mantendrá posteriormente cuando entre en acción la Orden Hospitalaria de San Juan de Dios.

Desgraciadamente, como sucede habitualmente a la hora de investigar temas referentes a la Edad Media o al Antiguo Régimen, la documentación conservada es mínima, y está, generalmente, en condiciones deplorables a pesar del esfuerzo de los archiveros.

Ya Fulgencio María de Heredia y Cabrera, autor en 1880 de la Memoria del Hospital de Beneficiencia de Cabra, se lamentaba de la falta de documentación sobre la Cofradía de la Caridad '.

Una de las primeras referencias documentales que poseemos proviene de la escritura de donación realizada por Fernán González de Estepa, el 15 de julio de 1517, ante el escribano Antón de Pareja, donde se nombra al "hospital... que ahora nuevamente se hace..." ${ }^{2}$.

Mayor información se obtiene de la copia autorizada por el escribano Alonso de Jerez el 30 de diciembre de 1563, del testamento otorgado por el Vicario Diego Hernández de la Cruz ante el escribano Luis Pérez, realizado el 12 de octubre de 1545, un día antes del fallecimiento del testador ${ }^{3}$.

' Fulgencio María Heredia Cabrera: «Memoria del Hospital de Beneficiencia de Cabra", en Moaxaja $n^{\circ}$ 2, 1984. Con estudio preliminar de José Calvo Poyato y Antonio Moreno Hurtado.

2 AMC-SR (Archivo Municipal de Cabra-San Rodrigo)-12-14).

${ }^{3}$ Ibidem, AMC-SR-12-9. 
Confirma en su testamento la existencia de los dos hospitales citados con anterioridad, y situados en el barrio de la Villa Vieja, junto a la Iglesia Mayor, y ya de fundación antigua.

El Vicario, poseedor de innumerables bienes según lo demuestra el inventario realizado a su fallecimiento, donará dos pares de casas en «... la collación de San Juan... y declaro y mando que siempre permanezcan los dichos pares de casas en el servicio de los dichos pobres... " ${ }^{4}$. Estas casas para hospital ya habían sido donadas por el Vicario anteriormente, pues, “... por cuanto en doce días del mes de diciembre del año mil quinientos veinte años el Magnífico Señor Don Pedro Ponce de León, Chantre y Canónigo de la iglesia de Córdoba, siendo Provisor en dicha ciudad y su Obispado por el llte. Rmo. Señor Don Alonso Manrique, Obispo..., viniendo a visitar las iglesias y hospitales de esta dicha villa de Cabra, viendo la necesidad que los pobres padecian en los hospitales viejos... y la buena disposición y edificios de casas que yo para ello daba... erigió en dicho día, mes y año las dichas mis casas que yo para el dicho hospital de pobres naturales y pobres peregrinos extranjeros di por hospital...” ${ }^{5}$.

Estas casas estaban situadas en la calle que a partir de este momento se denominará Hospitales, y sobre la que volveremos más adelante.

Como ya hemos indicado, los hospitales están regidos por una misma institución, la Cofradía y Hermandad de la Santa Caridad.

\section{Pero, ¿quién compone esta Cofradía?}

Fulgencio María de Heredia, ya mencionado, hacía ver la primacía de los regidores de la villa ocupando el cargo de Hermano Mayor. Esto es reiterado por los autores del estudio preliminar a la publicación del citado trabajo en la revista de la Casa de la Cultura de Cabra, Moaxaja 2.

Nosotros, recalcando la escasez documental, podemos añadir nuevos datos al tema.

\footnotetext{
${ }^{4}$ Ibidem, AMC-SR-12-9.

${ }^{5}$ Ibidem, AMC-SR-12-9.
} 
- La cofradía estaba compuesta efectivamente por laicos y eclesiásticos. De entre los primeros destacan los regidores, aunque en contados casos aparecen no regidores, como Alonso de Baeza, médico. A su cabeza existe un Hermano Mayor elegido "democráticamente" entre el resto de los componentes. Junto a él, hay unos coadjutores que controlan las decisiones tomadas por el superior; finalmente, el resto de los hermanos.

- El número de componentes es reducido. Así, en una reunión celebrada en 1574 para realizar el trueque de una propiedad de la Cofradía por otra pertenencia al Convento de Dominicos, los asistentes son nueve; un Hermano mayor, D. Diego Avís, tres coadjutores y cinco hermanos.

- Al mismo tiempo, el control de la institución se realiza en tres niveles: el ordinario eclesiástico, el Cabildo de la villa y el Duque de Sessa.

- El ordinario eclesiástico, en este caso directamente el Obispo, dictando provisiones para arrendar o vender propiedades, así como realizando visitas mediante sus vicarios ${ }^{6}$.

- Del Ayuntamiento, como se demuestra por un cuestionario realizado alrededor del año 1835 localizado en el Archivo Municipal de Cabra ${ }^{7}$, «... desde la memoria que hay de la fundación de dicho hospital se ha tenido y tiene por patrono de él a el llustre Ayuntamiento de esta villa, con respecto a que antes que pasase a dicha religión hospitalaria del Señor San Juan de Dios, corria con su manejo y dirección..., y en prueba de conservar su derecho tiene altar y Capilla en la colateral de la mano derecha donde se halla colocada la imagen del Señor San Rodrigo con el escudo de armas que tiene en el remate del retablo y de los que usa el Ayuntamiento, cuidando de dicha Capilla y haciéndole a sus expensas una función de Iglesia con el Señor Sacramentado y sermón asistiendo el Ayuntamiento".

${ }^{6}$ Ibidem, AMC-SR-4-1. Y en los libros de Visitas Eclesiásticas localizados en el Archivo de la Parroquia de la Asunción y Angeles de Cabra y en el Archivo del Obispado de Córdoba.

AMC-legajo 166, exp. 12. Sec. Beneficiencia, Ser. Hospitales. 
- Finalmente, el patronazgo directo de dicha Cofradía es ejercido por la Duquesa de Sessa, como lo demuestra la reunión del Cabildo para efectuar el trueque antes citado.

Esto sucede en una época donde los monarcas se ocupan, al menos en los que se refiere a legislación, de la asistencia a los pobres. Como sucede en la Pragmática dictada por Felipe II el 7 de agosto de 1565 sobre "establecimiento de hospitales en los pueblos a cargo de sus Justicias y Ayuntamientos para la curación de pobres llagados y capaces de inficionar" ${ }^{8}$.

Para concluir con esta primera etapa de la asistencia hospitalaria en Cabra, vemos como está presidida por la acción asistencial ejercida indirectamente por las clases altas de la villa, como miembros de la Cofradía y Hermandad de la Santa Caridad, dejando a "hospitaleros y hospitaleras" encargados de la asistencia directa en los hospitales, como lo indican los libros de Visitas Eclesiásticas conservados en el Archivo de la Parroquia de la Asunción y Ángeles de Cabra y en el Archivo del Obispado de Córdoba.

\section{DEL HOSPITAL DE SAN JUAN DE DIOS Y SAN RODRIGO AL HOSPITAL DE JESÚS NAZARENO}

Esta segunda etapa viene caracterizada por un cambio en la mentalidad asistencial: De la acción asistencial indirecta ejercida por la Cofradía de la Caridad, a la directa, mediante la Orden Hospitalaria de San Juan de Dios.

La llegada a Cabra de la Orden Hospitalaria de San Juan de Dios, para hacerse cargo de los hospitales de la villa, se produce en 1586.

No es la primera vez que este grupo acudia a Cabra. Ya, el fundador había estado en la villa, como lo demuestran las diferentes cartas cruzadas con la Duquesa de Sessa, una de las grandes protectoras del santo.

\footnotetext{
${ }^{\circledR}$ Nov. Rec, ley III, tít. XXXVIII, lib. VII.
} 
Por la importancia que la fundación de esta Congregación supone para el posterior desarrollo de la asistencia hospitalaria, es necesario analizar la personalidad de San Juan de Dios.

Después de una vida azarosa, $y$, según sus biógrafos, dirigida a la lucha contra el hereje, conoce en Granada a Juan de Ávila, clérigo, llamado «el Apóstol de Andalucía». Este acontecimiento marcará definitivamente la personalidad del fundador.

Juan de Ávila mantuvo unos importantes focos de espiritualidad en el Sur de la Península, y su pensamiento se resume en las palabras del profesor Andrés Martín.

“... San Juan de Avila recibió un muy particular conocimiento del misterio de Cristo en las cárceles de la Inquisición en 1530, según testifica el padre Granada que lo recogió de labios del Apóstol de Andalucía. La espiritualidad española, cristocéntrica y pasiocéntrica de por sí, se enriqueció más en este sentido. De no tratar a Cristo hay tanta sequedad y miseria, dice el Apóstol de Andalucía. Su preocupación, desde entonces es exaltar la grandeza del misterio de Cristo y la pequeñez y necesidad del hombre. Pocos son nuestros pecados, no en sí, mas comparados a los muchos merecimientos de Cristo, que nos dio lo que él ayunó, oró, y caminó y trabajó, y sus espinas y sus azotes y clavos, y hasta la muerte y vida, haciéndonos participantes en todo mediante los sacramentos y la fe. Cuántas son las misericordias del Señor, tantos podemos decir que son nuestros merecimientos, y cuántos son los bienes de Cristo, en tanto tenemos parte de nosotros..." ".

La pasión de Cristo como motivo de espiritualidad será tenida muy en cuenta por los discípulos de Ávila, quienes la practicarán tanto activa como pasivamente.

- La espiritualidad pasiva es aplicada por grupos de personas, fundamentalmente mujeres, con unas características especiales: la de tener independencia económica y vivir apartadas de lazos familiares, y serán perseguidas por la Inquisición al ser acusadas de alumbradismo.

${ }^{9}$ Melquiades Andres Martin (director): Los recogidos: Nueva visión de la Mística española. F.U.E., Madrid 1983. p. 100. 
- La espiritualidad activa es llevada a cabo por San Juan de Dios a partir de su contacto con el Apóstol de Andalucia, al escuchar su sermón en la granadina ermita de los Mártires, casualmente según sus biógrafos el día de San Sebastián, «especialísimo abogado de la peste" ${ }^{10}$. Esto supone la conversión definitiva del Santo y el momento culminante de sus futuras acciones.

En este momento, San Juan de Dios «... acompañado de una gran muchedumbre llega a su tienda y destruye cuanto hay en ella que no sean libros e imágenes piadosas. Distribuye el dinero que había ahorrado entre los pobres. Las imágenes y los libros piadosos los entrega gratuitamente a quienes se los piden, y cuando ha liquidado de esta manera todas sus existencias, reparte sus mismas ropas, quedándose únicamente con lo preciso para cubrir su desnudez" "

Pasará al Hospital Real granadino por su aparente locura, donde, según su biógrafo fray Juan Santos, criticará la falta de asistencia con los enfermos, "ien qué se gastan las muchas y muy gruesas rentas que los Reyes Católicos dejaron para la cura y asistencia de los pobres?" ${ }^{12}$, dirá el Santo.

Ávila a partir de este momento comenzará a encaminar las acciones de San Juan de Dios: lo enviará a Guadalupe, donde existía una excelente escuela de medicina dirigida por los jerónimos, aunque algunos biógrafos indiquen que la asistencia al Monasterio era con motivo de realizar una peregrinación.

A continuación iniciará la fundación de sus hospitales en Granada, pasando a la asistencia directa de los enfermos pobres. Al mismo tiempo recibirá el apoyo de grandes familias nobiliarias andaluzas, en su mayoría con sangre conversa al igual que su maestro Ávila y el Veinticuatro granadino García de Pisa, gran protector del Santo en los últimos momentos de su vida. Asimismo contará con el apoyo del Arzobispo granadino Don Pedro Guerrero.

${ }^{10} \mathrm{Fr}$. Juan SANTos: Cronología hospitalaria y Resumen Historial de la Sagrada Religión de/ Glorioso Patriarca San Juan de Dios", Madrid 1715 (edición modernizada y publicada por la Orden Hospitalaria de San Juan de Dios, Madrid 1977).

"Juan O. H. Ciudad Gomez: Historia de la Orden Hospitalaria de San Juan de Dios. Archivo Interprovincial, Granada 1963.

${ }^{12}$ Santos, Ibidem, nota 10. 
La espiritualidad pasiva, unida al cuidado de los enfermos, como le había indicado su maestro Ávila, aparece continuamente en sus escritos. Veamos algunos ejemplos:

«No hallo mejor remedio ni consuelo para cuando me hallo apasionado que es mirar y contemplar a Jesucristo crucificado y pensar en su pasión santísima y los trabajos y angustias que padeció. Nunca más pecar por sólo Jesucristo. Confiando en sólo Jesucristo y por sólo su amor y bondad no pecar ni murmurar ni hacer mal ni daño al prójimo. Hemos de dar gracias a Jesucristo porque usa con nosotros de tanta misericordia» (de la 2. ${ }^{\text {c }}$ carta a la Duquesa de Sessa).

"Cuando os viéredes apasionada, recorred a la pasión de Jesucristo Nuestro Señor y a sus preciosas llagas y sentiréis gran consolación" (de la 1. a carta a la Duquesa de Sessa).

San Juan de Dios nunca se preocupó de institucionalizar la comunidad creada; sus compañeros, al principio, tampoco. En esto sigue igualmente el ejemplo de su maestro Ávila; pues éste, después de crear "escuela", tanto a nivel de grupos de beatas como de inspirador de colegios y universidades (Priego, Baeza), sin embargo, nunca intentó institucionalizar su movimiento espiritual. Esto, tal vez, hizo que la obra de Ávila no fuese reconocida con la canonización hasta nuestros dias; al mismo tiempo, como indica el profesor Avilés, la no institucionalización, pudo derivar en degeneración o desviación ${ }^{13}$.

El inicio de la institucionalización vino cuando Pio $V$ quiso cortar los brotes de desviacionismo religioso, pues habia individuos que vivían en comunidad con hábito distinto de los seglares y sujetos a un superior, sin profesar una regla ni hacer los votos sustanciales a toda religión, y expidió el 17 de noviembre de 1568, dieciocho años después de haber muerto San Juan de Dios, la Bula Lubricum vitae genus, por la cual obligaba a tales a declarar dentro de las veinticuatro horas de haber tenido conocimiento de la Bula si querían hacer o no la profesión religiosa bajo unas reglas aprobadas. $Y$ en caso afirmativo, en un mes deberian hacer la profesión solemne de los tres votos sustanciales.

${ }^{13}$ En Axerquía n. ${ }^{\circ}$ 6. p. 206. 
Este intento de evitar el desviacionismo o la heterodoxia se da en un momento en el que la Inquisición española estaba investigando distintos focos de espiritualidad marginada, como sucede con los grupos de alumbrados que habían seguido las doctrinas del padre Ávila. No se debe olvidar el Auto de Fe del tribunal cordobés que en 1590 condenará al grupo de alumbrados jiennenses de Gaspar Lucas, no vinculados al avilismo, pero sí paralelos al grupo de Baeza; y una de las beatas será condenada a servir en el hospital granadino de San Juan de Dios.

Una vez transmitida por el Arzobispo Guerrero el contenido de la Lubricum vitae genus a la comunidad de Granada, el hermano Rodrigo de Sigüenza comienza a hacer los preparativos para la institucionalización de la Orden. Para esto, en 1571 acuden a Roma los hermanos Sebastián Arias, nacido en Carcabuey, y Pedro Soriano, natural de Bujalance, futuro Primer General de la Orden. Del Papa Pio V obtendrán el Breve "Salvatoris Nostri» y la Bula Licet ex debito, con la que quedaba aprobada la Congregación hospitalaria.

Sin embargo, las primeras constituciones, dadas para el hospital granadino no se elaborarán hasta 1585, un año antes de la llegada a Cabra del hermano Baltasar para hacerse cargo de la administración de los hospitales.

El Ilmo. Sr. D. Antonio de Pazos, Obispo de Córdoba, dará al hermano Baltasar la Provisión y Despacho para hacerse cargo de los hospitales de la villa.

No hemos encontrado ni originales ni copias del citado documento, pero si existen referencias:

«... por este motivo y el de contar con una Provisión y Despacho al parecer dado por el Ilmo. Sr. D. Antonio de Pazos, Obispo que fue de la ciudad de Córdoba, firmado de su mano, sellado con el sello de sus armas, y refrendado de Jerónimo de la Vega, su secretario, con fecha de veintinueve de mayo del año pasado de mil quinientos ochenta y seis, su data en dicha ciudad: Que al tiempo que su litma. nombró por Hermano Mayor de este hospital de la Caridad al hermano Baltasar, religioso que fue de dicha Orden, cediéndole asi al susodicho como a los demás hermanos que eran, y nombrase a tal Administrador que con el cargo que sirviesen a los pobres, asi enfermos de la tierra como peregrinos que iban de paso, conforme a la voluntad y voluntades de los que lo habian fundado y dotado con la calidad de que habían de decir las misas y que el capellán estaba obligado, dándole la facultad 
de entrar en las casas de dicho hospital, y tomar la posesión real... de ellas, y de todos los bienes raices y muebles que tuviese, que con efecto la tomó judicialmente..." ${ }^{14}$.

A partir de esa fecha, la Cofradía de la Caridad, como tal, desaparece, y en los primeros años los diferentes hermanos de la Orden Hospitalaria que actúen como encargados, llevarán el título de Hermano Mayor.

El interés del hermano Baltasar se centrará en la erección de un nuevo centro, que en un primer momento se quiere situar en el lugar ocupado en la actualidad por el Parque Público «Alcántara Romero". Para este fin acudirá a Madrid, con dinero librado por el Cabildo de la villa ${ }^{15}$, para que

“... pagase los derechos en hacer las diligencias en el Consejo Real y mensajero que ha de llevar los papeles de los remates de las obras de la cárcel y hospital que se ha de hacer en esta villa..." ${ }^{16}$.

De este viaje obtendrá una Real Cédula fechada en Madrid a 5 de noviembre de $1588{ }^{17}$ para la creación de un hospital:

«El rey: Por cuanto por parte de vos el Concejo, Justicia y Regimiento de la villa de Cabra nos fue hecha relación que en ella habia un hospital, el edificio del cual era muy antiguo y la casa muy estrecha y de poco sitio y aposento, de manera que los pobres padecian gran necesidad por no haber aposentos donde recogerlos y cerca de él no habia comodidad para poderle ensanchar y así se había tratado de mudar y hacerlo en otro sitio, propio del dicho hospital en una tierra suya junto a esa villa cerca de una ermita, donde había huertas y recreación para los pobres...".

14 AMC-SR-11-1-52.

15 AMC-A(ctas) C(apitulares) - Cabildo de 23 de agosto de 1588 (cuentas).

16 Ibidem nota 15.

${ }^{17}$ HEREDIA, op. cit. nota 1. 
Una vez realizados los trámites, la construcción del edificio se encontrará con la oposición de los Dominicos, tal vez debido a la proximidad con su Convento; por lo que finalmente se deciden a ampliar el antiguo hospital de peregrinos.

La oposición que ejercerá el Convento de dominicos no será el único problema que la Orden de San Juan de Dios tenga en Cabra. Habrá continuos conflictos jurisdiccionales con el ordinadio eclesiástico, tanto por el control de las visitas eclesiásticas al hospital como por el pago de los diezmos; con los dominicos, además de la situación ya planteada, por la ubicación del Colegio de Estudios Mayores de la Purísima Concepción así como por otros asuntos; y por último, con el Cabildo de la villa por una deficiente asistencia a los enfermos en diferentes ocasiones.

El hospital de San Juan de Dios, manteniendo la dualidad de casas para pobres naturales y peregrinos forasteros, se sustentará como único centro asistencial permanente en la villa hasta la aparición del hospital de Jesús Nazareno y Escuela de Cristo.

Hemos dicho el único centro asistencial permanente en la villa, pues además de existir alguna institución que se hiciese cargo de la visita a pobres y enfermos, como la Cofradía del Espíritu Santo, en tiempos de epidemia se crean hospitales de emergencia.

Esto sucede en 1651, cuando el Cabildo de la villa toma el acuerdo de crear un hospital para apestados ${ }^{18}$, ubicado en la ermita de San Juan Bautista del Cerro, y ya utilizado en anteriores epidemias.

El motivo de esta elección se debió a que dicha ermita estaba situada en uno de los límites de la villa, pues el hospital de San Rodrigo, localizado en el centro de la población, quedaba para acoger a otros enfermos.

Es importante destacar este hecho por la diferencia establecida con respecto a Córdoba. Alí se utilizó el hospital de San Lázaro, regido por los hermanos de San Juan de Dios, para tratar a los afectados de peste, por estar situado extramuros de la ciudad.

\footnotetext{
18 AMC-AC-1651.
} 
De esta forma la Orden Hospitalaria se va a mantener relativamente alejada de la epidemia. Señalamos la relatividad de esta circunstancia, pues algunos aparecen entre los fallecidos en el hospital de contagio. Además, aportarán a la ermita de San Juan Bautista cuatro camas completas, siendo esto motivo posteriormente de pleito con el Concejo de la villa, cuando pasada la epidemia, el Prior Fr. Sebastián Malo de Molina reclama al Ayuntamiento los 120 ducados en los que estaban tasados dichas camas ${ }^{19}$.

Junto a la utilización de la ermita, las calles que la rodean se cercarán y sus casas empleadas como lugar de convalecencia.

Otras ermitas, la de San Sebastián y la del Calvario, situadas extramuros, servirán como recintos para que las personas vinculadas a los contagiados pasasen la cuarentena.

Un hecho anecdótico, pero en consonancia con la diferenciación social de la época, se produce al existir un tratamiento desigual entre apestados nobles o pertenecientes al pueblo llano.

Así, mientras el Corregidor prohibe a los vecinos el ocultar la enfermedad, y exige al que se sienta enfermo lo comunique al médico; y si en efecto está apestado, ingresará inmediatamente en el hospital de S. Juan Bautista, bajo pena de doscientos azotes si desobedece la orden ${ }^{20}$. Sin embargo, en una reunión celebrada por la "Junta de la Salud y Defensa del achaque", de la que formaba parte el Corregidor, se toma el acuerdo de consultar

«... a su Excelencia el Duque... que si lo que Dios no permita, toca el achaque en algunos señores sacerdotes o de orden sacro y de las personas de calidad, así hombres y mujeres, que estos se hayan de curar en sus casas en aposento aparte..." ${ }^{21}$.

19 AMC-SR-13-1.

${ }^{20}$ Auto del 3 de agosto de 1651. AMC-leg. 169, exp. 2. Sec. Sanidad, Ser. Hospitales.

${ }^{21}$ Junta del 5 de julio de 1651. AMC-leg. 169, exp. 2. Sec. Sanidad, Ser. Hospitales. 


\section{3. ${ }^{a}$ ETAPA: DEL HOSPITAL DE JESÚS NAZARENO A LA DESAMORTIZACIÓN ECLESIÁSTICA EN EL XIX}

La tercera y última etapa en la asistencia hospitalaria de Cabra durante la Edad Moderna comienza con la fundación, el 15 de agosto de 1669, de la Congregación y Escuela de Cristo

«... conforme a las Constituciones de la que esta en Madrid en el Hospital de los italianos...»22.

Pronto la Junta de Ancianos de la Escuela de Cristo va a decidir la creación de camas para atender a los pobres convalecientes, pues la Escuela,

"... siendo madre de muchas que hay en esta Comarca, sea la única que no ha logrado el alivio de labrar oratorio para el culto de su divino maestro, y porque uno de los dichos hermanos hace donación de un sitio capaz de fabricarle y se hallan con mil ducados para su costo, se presentan a Vuestra llustrísima su buen deseo y el que tienen de mayor alivio de los pobres para cuyo efecto, y lograr continuas ocasiones de ejercitarse en obras que acrediten el buen fin de su congregación, ha propuesto poner tres camas en una sala a destinar para el recogimiento de los pobres convalecientes que, despedidos del hospital por falta de abrigo y regalo, suelen recaer en graves dolencias y enfermedades..." ${ }^{23}$.

Don Francisco de Alarcón, Obispo de Córdoba, concede la pretensión de la Junta de Ancianos, el 11 de diciembre de 1674.

En mayo de 1686 entra en funcionamiento el hospital, encargando, para la asistencia de enfermos, a una hermana que había sido enviada del hospital de Jesús Nazareno

"... de la ciudad de Córdoba y otra que entró de esta villa (de Cabra), que ambas están dedicadas a la curación y servicio de los pobres enfermos..." ${ }^{24}$.

\footnotetext{
22 AMC-J(esús) N(azareno)-13-2.

23 AMC-JN-13-2, y AMC-JN-7-1, folio 43/v.

${ }^{24}$ Ibidem, AMC-JN-13-2.
} 
El engrandecimiento del hospital vendrá a través de las donaciones realizadas por Don Sebastián Andia de Cuéllar, Rector de las Iglesias de la villa, y por el licenciado Don Juan Francisco Gómez Seto, presbítero y notario del Santo Oficio, por escritura otorgada ante el escribano Antonio Francisco Castroverde, el 24 de noviembre de 1691. Cada uno de ellos donará doce mil ducados para que

«... hagan unas camas de enfermos y salas de convalecientes $e$ incurables para mujeres; y otras dos salas para hombres convalecientes que salieren del hospital de San Juan de Dios, la una, y la otra de hombres incurables, obligándose dicho hospital y nosotros en su nombre a tenerlos y darle todo lo necesario para sus alimentos y criando en cada un año tres niñas de la puerta de la Iglesia..." ${ }^{25}$.

Como vemos, el hospital se va ampliando. Sin embargo, en el aspecto de la mentalidad asistencial existen diferencias fundamentales con respecto al hospital de San Juan de Dios.

En el regido por los hermanos de la Orden Hospitalaria, éstos se hacen cargo de la asistencia directa a los enfermos; la "caridad cristiana" con respecto a los pobres es aplicada directamente.

Sin embargo, en el Hospital de Jesús Nazareno y de la Escuela de Cristo, se intenta llegar a la "salvación eterna" mediante obras de Caridad, como son donativos, “... enseñar a los ignorantes los preceptos de Dios..." ${ }^{26}$, introducir la paz entre los enemigos, asistir a entierros, etc., pero el trabajo de asistir directamente a los enfermos recae en otras manos.

Esto se observa cuando, en 16 de agosto de 1730 el Padre Obediencia de la Escuela de Cristo, Don Pedro Arcadio de la Bella y Ahumada, Rector y cura de las Iglesias de la villa

«... viendo que en el santo hospital sito en dichas escuelas de Cristo, no se asistía a los pobres enfermos con aquella puntualidad, asistencia y caridad que se requiere, por ser quien las asistía mujeres

${ }^{25}$ Ibidem, AMC-JN-8-9.

${ }^{26}$ Ibidem, AMC-JN-13-2. 
asalariadas que más miran a su provecho y comodidad que a la conveniencia y buen cuidado de las enfermas; se determinó con el parecer de la Venerable Junta de Ancianos de dicha Escuela, escribir al... Obispo de Córdoba, pidiéndole y suplicándole, que como en dicha ciudad había dos hospitales, que con toda edificación y caridad cuidaban y asistian a los entermos..., que sirviese concedernos unas hermanas de cualquiera de los dos hospitales de dicha ciudad, para que en este hospital de Jesús Nazareno de esta villa de Cabra, se extendiese tan Santo Instituto y se ejerciese la Caridad con aquel esmero y puntualidad que en dichos hospitales se ejercía, porque nuestro deseo fue, es y será siempre, que las pobres enfermas de este hospital estén asistidas de toda solicitud, diligencia, y cuidado posible, sin que haya la menor omisión.

A cuya súplica, como tan caritativo y celoso Señor (Obispo) se sirvió conceder y condescender a ella, concediéndonos cuatro hermanas del Santo Hospital del Señor San Jacinto de dicha ciudad... y expidió un Decreto... el cual hoy no aparece... (en el que se indicaba) que el Capellán de este hospital fuese el Director de dichas hermanas, y que en ningún tiempo tuviese la Venerable Junta intervención... $Y$ el día veinte de agosto de dicho (año) entramos en Cabra con cuatro hermanas que nos concedió (el Obispo)..." ${ }^{27}$.

El mismo Padre Obediencia, autor del relato, entrará como capellán del hospital en 1744.

A partir de esta fecha ambos hospitales, S. Rodrigo y Jesús Nazareno, continuarán funcionando normalmente hasta el inicio del siglo XIX, cuando comenzarán a tener problemas desde la llegada de los franceses. Nacionalizados en 1810, y durante el Trienio-Liberal, acabarán definitivamente a partir de la Desamortización eclesiástica, siendo unificados en un hospital dependiente del Ayuntamiento a través de la Junta de Beneficencia.

Este hospital, trasladado al desamortizado Convento de dominicos, permanecerá hasta los años setenta de nuestro siglo.

Hoy, como evidentemente se puede observar, la situación hospitalaria de la ciudad de Cabra, así como su mentalidad asistencial, ha registrado un giro copernicano.

${ }^{27}$ AMC-BEN(eficencia)-36-1. 


\section{CONCLUSIÓN}

Para concluir, y una vez estudiada la situación asistencial de la villa de Cabra durante la Edad Moderna, podemos analizar algunas líneas de investigación abiertas por la documentación emanada de una institución hospitalaria.

Junto a los aspectos puramente asistenciales, innatos a todo hospital, otros apartados a estudiar serían:

- La mentalidad de los fundadores, tanto si se trata de un hospital regido por gremios, particulares, comunidades religiosas o patrocinado directamente por el Rey. Si actúa como organismo autónomo o dependiendo directamente de jerarquias superiores.

- La inserción del hospital en una comunidad determinada, posibilita el estudio de las relaciones del centro asistencial con las instituciones de la localidad, Ayuntamiento, comunidades religiosas, y otros.

- Asimismo, como sucede en los hospitales de San Juan de Dios, permite tanto el estudio de las relaciones supranacionales, por ejemplo la separación de la provincia portuguesa de la Congregación española, como de la realidad política de España.

- Finalmente otro aspecto importante es el estudio de la economía de la institución, basada primordialmente en su autosuficiencia a través de las distintas propiedades urbanas y rurales, así como bienes muebles, que componen su patrimonio. Esto, unido a ese excelente útil de trabajo que para los investigadores de la Edad Moderna supone el Catastro del Marqués de la Ensenada.

Con el planteamiento de estas líneas de investigación abiertas, y en las que actualmente estamos trabajando, finalizamos el trabajo referente al estudio social de la asistencia hospitalaria en Andalucía, atendiendo al caso de Cabra. 